\title{
30
}

\section{Regional Hydrological Modeling of City of Tshwane Municipality using VisualSWMM}

\author{
R.J. Males, M. Braune, D. Van Bladeren and D. Mahlangu
}

In order to develop an integrated catchment management plan for present and future development scenarios, the City of Tshwane Metropolitan Municipality (CTMM), situated in Gauteng province, South Africa, required integrated data on runoff peaks and volumes along all its major watercourses amounting to approximately $1400 \mathrm{~km}$. This is focussed towards improving the planning and management of stormwater drainage systems in all catchments within its area of jurisdiction.

CTMM thus commissioned SRK Consulting (Pty) Ltd to compile a regional hydrological model of all its major watercourses as well as a river referencing system (RRS) and stormwater management information system (SMIS) to aid in managing the data.

The main objectives of the project can be summarised as follows:

- review all available data (rainfall, runoff, catchment, landuse);

- define the locality and nature of existing major drainage systems;

- establish integrated intensity-duration-frequency relationships;

- establish integrated design runoff hydrographs along major drainage systems and watercourses;

- establish a RRS giving digital and visual information of all existing floodline data, scanned images, spatial and numeric data; and

- compile a SMIS for easy access and queries of the data.

Males, R., M. Braune, D. van Bladeren and D.J. Mahlangu. 2004. "Regional Hydrological Modeling of City of Tshwane Municipality using VisualSWMM." Journal of Water Management Modeling R220-30. doi: 10.14796/JWMM.R220-30.

(C) CHI 2004 www.chijournal.org ISSN: 2292-6062 (Formerly in Innovative Modeling of Urban Water Systems. ISBN: 0-9683681-9-0) 
This chapter presents the derivation of the CTMM hydrological model generated in VisualSWMM covering an area of approximately $2300 \mathrm{~km}^{2}$. It describes a generic approach followed towards deriving a master drainage plan including data collection, catchment and watercourse delineation, rainfall analysis and the generation of the hydrological model, including calibration and verification, to be used as decision support for catchment management.

\subsection{Hydrological Modeling and Catchment Management}

Catchment management can be seen on one level to be concerned with addressing critical water resource problems in an integrated manner, based on a thorough understanding of the causes and effects of those problems (Görgens et al., 1998).

Hydrological information obtained from regional catchment hydrology for major drainage systems is thus essential in integrated development planning. It is also a further requirement for

- reliable flood line determination;

- verification and calibration of minor stormwater drainage system models used for local stormwater master plans; and

- assistance in the integrated planning of roads, other infrastructure and urban development.

This understanding of catchment resources and their interactions is fundamental to sound decision making and is obtained through a combination of detailed assessment of available information and catchment hydrological modeling (Görgens et al., 1998).

The choice of which model to use is related to the desired level of complexity, with the appropriate level of analysis dependent upon: (Yen, 1994)

- objective and approach taken - continuous (historical) vs. eventbased (design) analysis;

- output information needed and require accuracy - design discharge or runoff hydrographs;

- available data - drainage network (pipes, catchpits, junctions), catchment (topography, impermeability, soil characteristics), rainfall (spatial and temporal);

- tools available - computer capability and numerical techniques; and 
- flow conditions - network, catchment properties, roughness, Froude numbers

For a particular modeling application it is thus necessary to define the desired complexity and information required based on available data. Clear formulation of the model goal must be attained initially. Questions such as desired accuracy of results, degree of uncertainty in the provided answers, time scale of the solution, system boundaries, important variables, environmental conditions etc., need to be addressed in order to select the most appropriate modeling approach.

\subsection{Applications of GIS to Hydrological Modeling}

It is necessary to recognise that many of the parameters and input data for hydrological models are derived from geographically referenced physiographic information (topography, geology, soils etc). The time consuming task of data capture and manipulating can be most easily carried out using a geographical information system (GIS) (Herald, 1991).

GIS can be defined as a computerised system for the creation, storage, analysis and display of data of either a spatial or non-spatial nature (Fisher and Wijers, 1991). It can also be considered as a decision support system involving the integration of spatially referenced data in a problem-solving environment (Cowen, 1988).

The value of GIS thus stems from its relational database facility, which enables the manipulation of both spatial and temporal information. This can provide the hydrological modeler with a powerful tool for determining model input parameters and for the compiling and managing of input data, especially that for distributed physically based models (Herald, 1991). In addition, it is used for the following applications (Fisher and Wijers, 1991):

- input of spatial data (rainfall, topography, catchment and subcatchment boundaries, dams, etc.);

- spatial analyses (through either the preparation of data for input into the model such as calculation of subcatchment areas, subcatchment slopes, determination of overland flow lengths and slopes or the analysis of model output);

- spatial representation (digital maps permitting graphical queries from users and decision-makers). 


\subsection{Generation of CTMM VisualSWMM Model}

\subsubsection{Overview of CTMM Jurisdiction}

The City of Tshwane Metropolitan Municipality (CTMM), previously the City of Pretoria Municipality, comprises an area of approximately $2300 \mathrm{~km}^{2}$. It has a variety of landuse ranging from dense urban development to rural agricultural and undeveloped. The upper third of the municipal area is bisected by the Magaliesberg mountain range whilst the western Hennops River catchment is dolomite dominated.

Table 30.1, provides an indication of the major river catchment systems within the CTMM jurisdiction with the associated length of main stem channels and tributaries and the number of subcatchments demarcated during the modeling exercise.

Table 30.1 Principal river catchment systems within the CTMM jurisdiction.

\begin{tabular}{lccc} 
Catchment & $\begin{array}{c}\text { Total Catchment } \\
\text { Area (ha) }\end{array}$ & $\begin{array}{c}\text { Total Length } \\
\text { of conduits (km) }\end{array}$ & $\begin{array}{c}\text { Number of } \\
\text { subcatchments }\end{array}$ \\
\hline Apies & 68557 & 188.1 & 136 \\
Hennops & 60729 & 163.4 & 84 \\
Sand & 29633 & 68.5 & 54 \\
Pienaars & 29086 & 85.1 & 43 \\
Soutpansburg & 14530 & 35.4 & 32 \\
Stinkwaterspruit & 13617 & 40.3 & 23 \\
Swartspruit & 12812 & 18.5 & 13 \\
TOTAL & 228964 & 599.3 & 385 \\
\hline
\end{tabular}

\subsubsection{Overland Flow Generation}

As an alternative to the non-linear runoff routing method employed by RUNOFF, VisualSWMM offers the option of overland flow generation with the well-established SCS method. Given the availability of good soil and land use data and associated curve number information for present and past degrees of urbanisation this SCS method was selected for the generation of runoff hydrographs.

Input data for the RUNOFF module requires two tasks:

- discretisation of physical drainage system

- estimation of subcatchment coefficients 
Physical drainage system

Data was obtained from a number of different sources for use within ArcView GIS in order to digitally define the physical drainage system. These sources are indicated in Table 30.2.

Table 30.2 Sources of GIS data.

\begin{tabular}{lll}
\hline Data type & Source & Description \\
\hline Landuse & CTMM & $\begin{array}{l}\text { ArcView shapefiles indicating present and } \\
\text { future Landuse type for Tshwane area } \\
\text { ArcView shapefile indicating boundary extents } \\
\text { of municipal area }\end{array}$ \\
$\begin{array}{l}\text { Municipal } \\
\text { boundary } \\
\text { Rainfall }\end{array}$ & CTMM & Smithers and Schulze \\
(2002) & $\begin{array}{l}\text { Spatially representative rainfall depths and } \\
\text { DDF curves }\end{array}$ \\
Soils & Institute for Geo-Sciences & $\begin{array}{l}\text { ArcView shapefile indicating soils distribution } \\
\text { for CTMM area in terms of SCS classification } \\
\text { ArcView shapefiles indicating contours at 5m } \\
\text { interval }\end{array}$ \\
\hline
\end{tabular}

River centre lines were digitised from the 10,000 scale orthophoto maps. Information from previous reports and CTMM was used to obtain river names. River lengths were obtained using the ArcView extension. River slope was obtained using the 1085 slope method used by Department of Water Affairs and Forestry Flood Studies division.

Quaternary catchment delineation was undertaken with the use of WR90 (Midgley et al.,1994) to obtain principal river catchment boundaries. These quaternary catchments were subdivided into tertiary subcatchments based on the $5 \mathrm{~m}$ contour interval and the above identified river delineations. RUNOFF nodes were selected at subcatchment outflow points.

\section{Subcatchment parameter coefficients}

Subcatchment slope: This is the average slope assigned to both the pervious and impervious parts of the subcatchment. The overland flow slope of each subcatchment was obtained using an ArcView extension to generate a slope grid that was reclassified to compute area-weighted slopes per subcatchment.

Curve Number: The curve number (CN), as used in the SCS method of runoff generation, is a dimensionless number depending on hydrologic soil group, cover type, treatment, hydrological condition, and antecedent moisture conditions. This number has a valid range from 0 to 100 with typical values from 60 to 90 and 98 for impervious surfaces. 
Curve numbers were obtained through overlaying the soil distribution (in terms of SCS-SA classification) and landuse shapefiles with spatial analysis generating an area weighted curve number per subcatchment.

Time of Concentration: The time of concentration is defined in two ways; the time for runoff to travel from the furthermost point of the watershed to the point in question, and the time from the end of excess rainfall to the point of inflection on the trailing limb of the unit hydrograph.

The time of concentration can be calculated from a number of formulae including the SCS lag, channel Tc and overland flow Tc equations. A comparison of the results given by each formula in the calibration exercise discussed in section 5.3, below, revealed that the overland flow Tc equation, indicated in Equation 30.1, below, provided the best results for the CTMM model:

$$
T_{c}=0.604\left(\frac{r L}{S^{0.5}}\right)^{0.467}
$$

where:

$$
\begin{aligned}
T_{c} & =\text { time of concentration }(\mathrm{h}), \\
L & =\text { length }(\mathrm{km}) \\
S & =\text { subcatchment slope }(\mathrm{m} / \mathrm{m}), \text { and } \\
r & =\text { roughness coefficient. }
\end{aligned}
$$

\subsubsection{Derivation of Spatially Distributed Rainfall for CTMM}

Given a lack of sufficiently long-term, reliable rainfall data in the CTMM, it was required to obtain spatially distributed design rainfall depths across the CTMM for return periods ranging from 2 to $200 \mathrm{y}$. In a report to SRK Consulting, Smithers and Schulze (2002) estimated this design rainfall for various durations and for return periods for the CTMM's area of jurisdiction. This was to indicate the spatial variation in design rainfall depths for a given return period and duration within this study area. Regionalised depth-duration-frequency (DDF) rainfall curves were also developed.

The authors utilised regional frequency analysis to supplement the time limited sampling record of individual sites by the incorporation of data from different sites in a region. This is based on the assumption that regional frequency analysis assumes that the standardised variate has the same distribution at every site in the selected region and that data from a region can thus be 
combined to produce a single regional rainfall, or flood, frequency curve that is applicable anywhere in that region with appropriate site-specific scaling (Smithers and Schulze, 2002). This approach thus allows for the estimation of events at sites where no rainfall or runoff data exists.

Smithers and Schulze (2002) thus utilised a regional index-flood type approach to frequency analysis based on L-moments termed the Regional LMoment Algorithm (RLMA) in conjunction with the Scale Invariance (SI) of the growth curves relating the scaled design rainfall depth to return period to estimate short and long duration design rainfall in South Africa. This RLMA\&SI approach was applied to the CTMM to derive design rainfall depths for return periods ranging from $2 \mathrm{y}$ to $200 \mathrm{y}$.

Smithers and Schulze (2002) demarcated the CTMM into four distinct regions with similar distributions of short and long duration extreme rainfall and obtained DDF curves for each region. The temporal distribution of design storms estimated for the four regions were all found to conform to the SCS Type 2 rainfall distributions.

The four demarcated areas are shown in Figure 30.1 below. The regions, labelled, 16_1, 28_1, 16_11 and 19_1 are overlaid on the major catchment systems within the CTMM.

For the 24-h rainfall duration utilised in the SCS method, design rainfall depths were thus generated for recurrence interval storms ranging from the 1 in 2 to 1 in $200 \mathrm{y}$ events. These rainfall depths were applied to the subcatchments within the CTMM and thus allowed for spatial variation of rainfall across areas of differing rainfall conditions. The $24-\mathrm{h}$ rainfall depths as derived by Smithers and Schulze (2002) for the four different rainfall regions of the CTMM are summarised in Table 30.3:

Table 30.3 Spatially varied rainfall depths across CTMM for different return periods.

\begin{tabular}{ccccc}
\hline Return Period & \multicolumn{4}{c}{ 24 h Rainfall (mm) } \\
\hline (y) & MED16_1 & MED1611 & MED19_1 & MED28_1 \\
\hline 2 & 67.3 & 62.1 & 65.0 & 68.0 \\
5 & 93.0 & 85.8 & 88.3 & 92.7 \\
10 & 112.4 & 103.7 & 105.0 & 110.4 \\
20 & 133.0 & 122.8 & 122.1 & 128.4 \\
50 & 163.1 & 150.5 & 146.0 & 153.7 \\
100 & 188.4 & 173.8 & 165.3 & 173.9 \\
200 & 216.2 & 199.5 & 185.8 & 195.4 \\
\hline
\end{tabular}




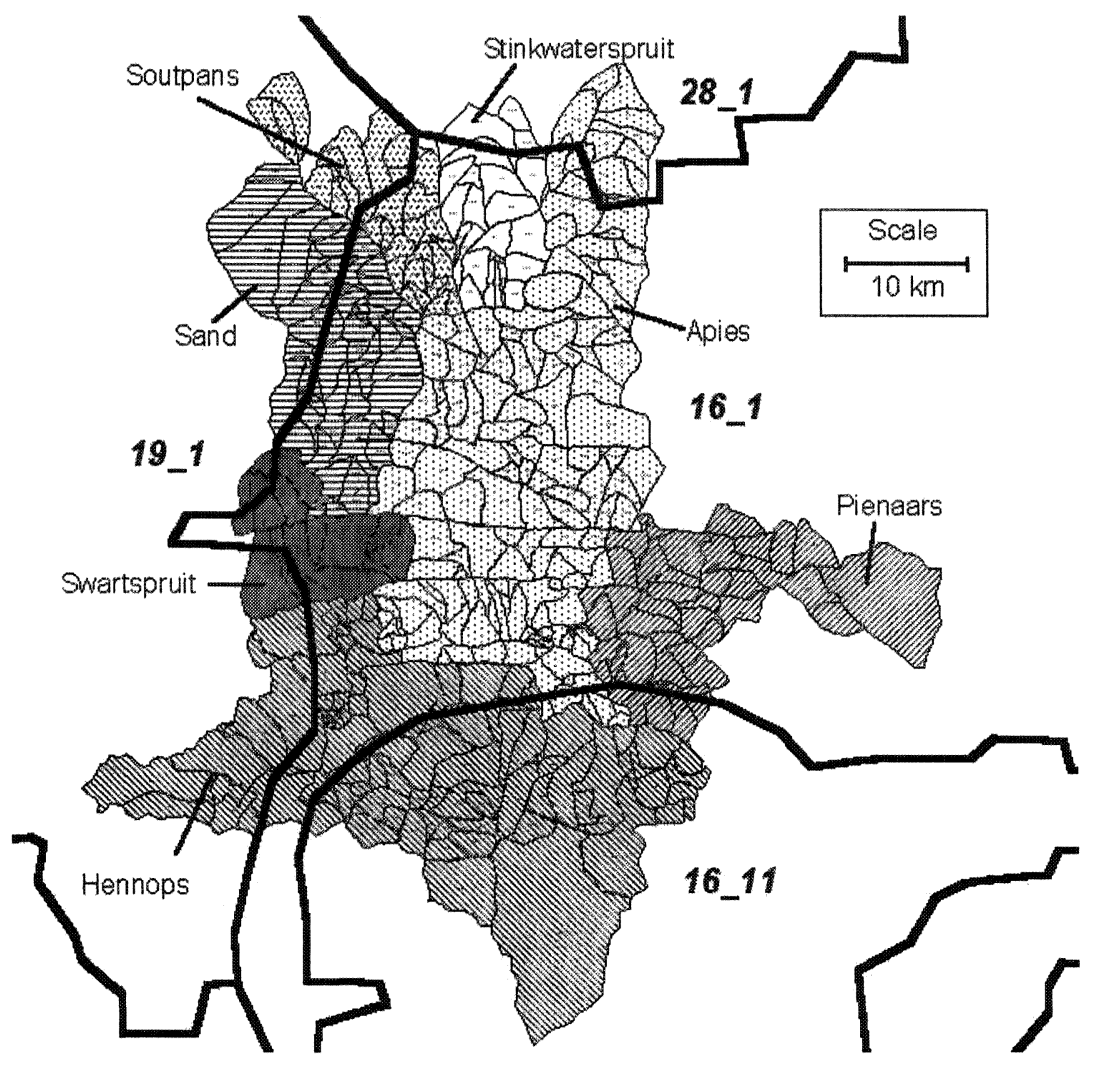

Figure 30.1 Rainfall regions within CTMM (Smithers and Schulze, 2002) and principal river systems.

\subsubsection{TRANSPORT Module}

Given the regional nature of the CTMM hydrological model, routing of the stored runoff hydrographs through the river system was accomplished in the TRANSPORT mode. TRANSPORT can be considered less data intensive than EXTRAN with corresponding savings during data collection and model generation. The considerable differences in conduit lengths also ensure that TRANSPORT is significantly more stable than EXTRAN with faster model run times. 
TRANSPORT utilises the kinematic wave formulation in which steady non-uniform flow conditions are approximated and disturbances are allowed to propagate in the downstream direction. No backwater effects are modeled and backwater conditions are assumed not to affect upstream computations. Any surcharging is modeled by storing excess flows at the head of the conduit until the capacity exists to accept the stored volume.

TRANSPORT allows the simulation of complex cross-section shapes including irregular cross sections as determined in HEC-RAS format. Stored hydrographs generated in the RUNOFF module are input into the TRANSPORT mode at nodes. The system is described as a network of conduits (or channels) joined at elements (manholes or another type of structure) with flow routing proceeding downstream through all the elements during each time interval until the storm hydrographs are routed through the system. Most of the data inputs are thus in terms of that needed to describe the conveyance system being modeled (dimensions, slopes, roughness etc).

TRANSPORT is appropriate for routing hydrographs when the effect of in-system storage and attenuation on the outfall hydrograph is significant. This is especially the case for large conduits with appreciable lengths and shallow grades or if detention storage is implemented in the system.

In addition to the RUNOFF nodes, TRANSPORT nodes were selected at appreciable changes in channel cross section. Where tributaries joined main stem channels, TRANSPORT nodes were situated at the outflow of the tributary and in the main stem above and below the tributary inflow. This allowed the evaluation of individual subcatchment flow contributions to the total routed flow in the main stem channel.

Conduit profiles were identified between TRANSPORT nodes to derive conduit length, average slope and Manning's $n$ roughness. Conduit crosssections were created using on screen digitising in ArcView GIS. The digitised lines were then converted into 3D sections using the ArcView extension (Profile Extractor). This allowed the selection of a representative cross-section per conduit that was imported into VisualSWMM in HEC2 format as an irregular section based on station - elevation pairs. Where cross-sections included an artificial channel, these channels were inserted in the irregular cross-sections with left and right overbanks and the corresponding change in Manning's roughness $n$ coefficient.

Control sections, represented by bridge and culvert openings, were identified in terms of upstream and downstream elevations, culvert shape and dimensions and number of barrels. Given the lack of adequate bridge routing capabilities in SWMM4, this initial series of TRANSPORT simulation runs 
considered the upstream node of the control section as a flow divider. Hydraulic analysis of the multi-barrelled bridge openings determined the flow capacity of the culvert. Flows in excess of this culvert capacity were routed over the bridge deck modeled as a trapezoidal cross-section of width equal to the total length of the bridge. Whilst this approach doesn't allow for backwater storage to be accounted for at these control sections, it does identify the flood magnitude at which bridge openings are insufficient and thus requiring attention in localised stormwater management plans. Subsequent CTMM model runs will consider these control sections as storage devices with outflow through the bridge opening determined from rating curve and a stage volume relationship upstream of the control section from channel invert to above bridge deck extracted from digitised contour maps in ArcView.

Storage reservoirs within the catchment were simulated with standard level-Puls reservoir routing techniques to route hydrographs through the reservoir. A relationship between depth, surface area, outflow and storage volume is required as input for this simulation. The relationship can be entered directly, or indirectly with outflow conditions of weirs, orifices, or pumps.

\subsection{VisualSWMM CTMM Model}

Figure 30.2, below, provides an indication of the model subcatchment discretisation taken from the upper $50 \%$ of the Apies River catchment by way of example. This subcatchment delineation is overlain on a map of the CTMM corresponding to the principal urbanised areas of the City of Tshwane.

The Apies River has its headwaters in Centurion, between Johannesburg and Tshwane, runs northwards through the centre of the City of Tshwane and drains into the Bon Accord Dam (indicated at top edge of Figure 30.2) before continuing north past the jurisdictional boundary of CTMM at Temba. The total length of main channel and tributaries is approximately $190 \mathrm{~km}$ with an average subcatchment size of $5 \mathrm{~km}^{2}$.

An example of the model setup for the Apies River catchment is shown in Figure 30.3, below, with the Apies River and an additional tributary draining into the Bon Accord Dam, north of Tshwane.

Analysis of Figure 30.3 reveals that two conduits, CAP43993 and CAPMR2155, drain into the Bon Accord Dam Storage node. Each subcatchment in the model was assigned a node number based on the HECRAS river stationing system (which is the distance from the most downstream point) for its most downstream node and a prefix defined by its associated river name (for the 


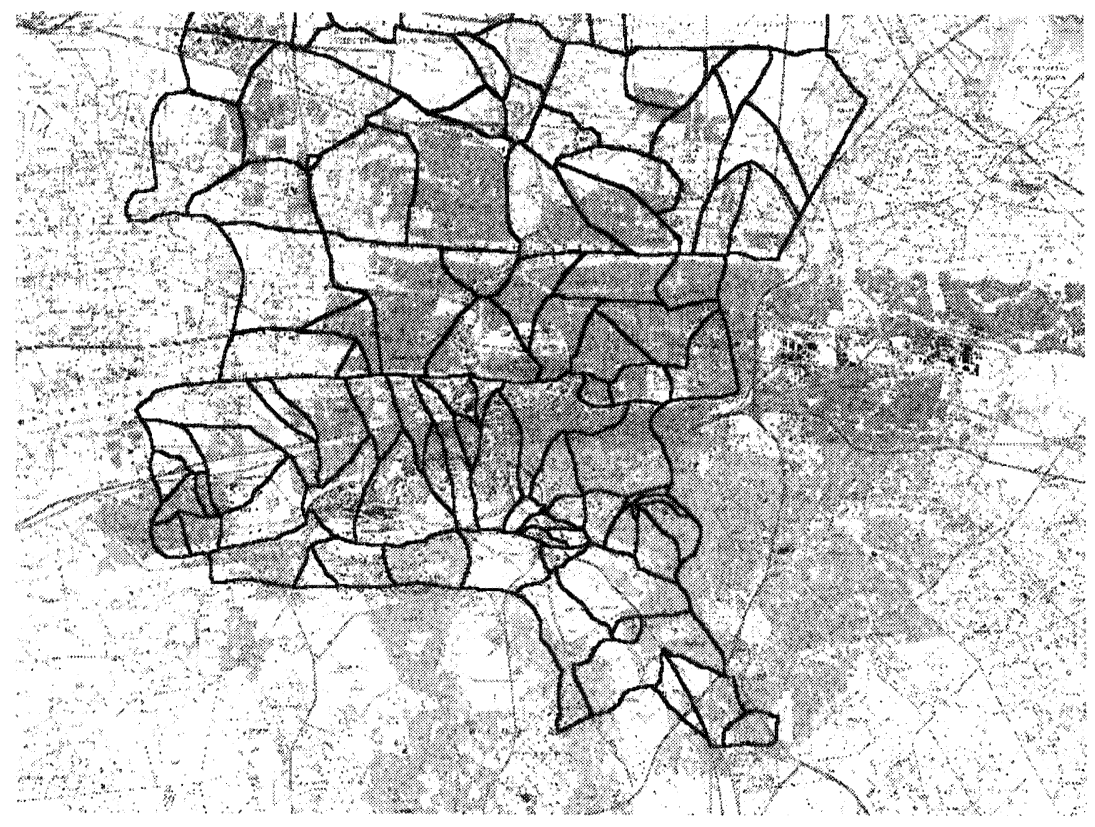

Figure 30.2 Subcatchment discretisation of upper Apies River catchment.

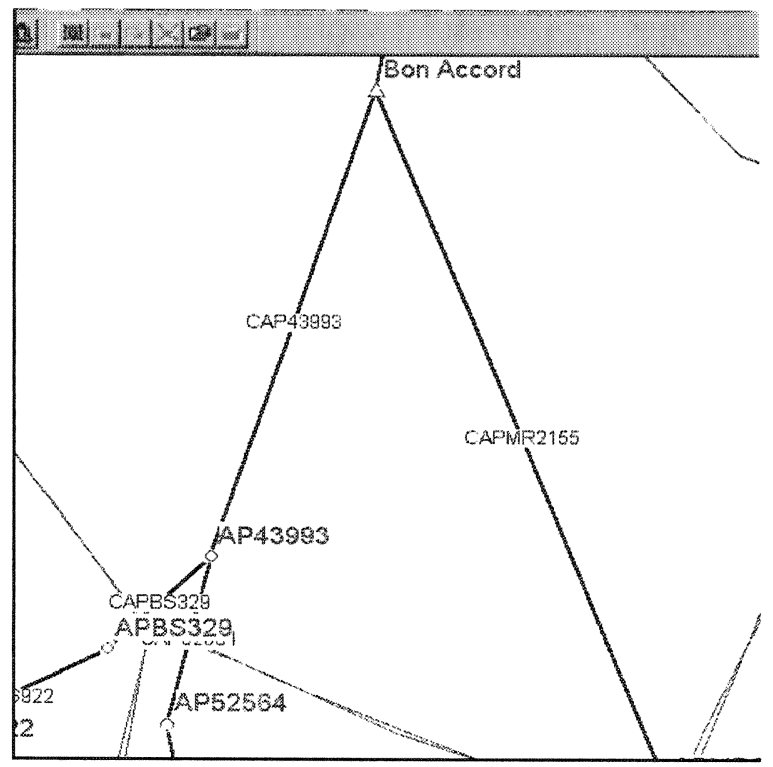

Figure 30.3 Snapshot from Apies River catchment model. 
shown case : AP - Apies). Conduits were named after the upstream node with a prefix " $\mathrm{C}$ " indicating it as conduit.

From Figure 30.3, it can be seen that two subcatchments drain to node AP43993 from nodes AP52564 and APBS329. These two nodes are both RUNOFF and TRANSPORT nodes and thus allow for the determination of overland flow (if accessed from RUNOFF mode) or total routed flow to that node (if accessed from TRANSPORT node). This is geared towards both master drainage plans that consider the entire catchment or localised subcatchment drainage plans based on flows from individual subcatchments.

For example, for a 1 in $100 \mathrm{y}$ storm, the difference in flows for the two nodes is shown in Figures 30.4 and 30.5, with $8.9 \mathrm{~m}^{3} / \mathrm{s}$ of overland flow contributed from the subcatchment at Node APBS329 whilst the total routed flow of all upstream catchments (including the overland flow contribution of $8.9 \mathrm{~m}^{3} / \mathrm{s}$ ) to Node APBS329 is $231.9 \mathrm{~m}^{3} / \mathrm{s}$.

Routed flows in TRANSPORT were thus examined at the nodes corresponding to river gauging stations where calibration peak flows were to be determined. Prior to calibration, however, a sensitivity analysis was undertaken on the model to determine key parameters to be perturbed in the calibration process.

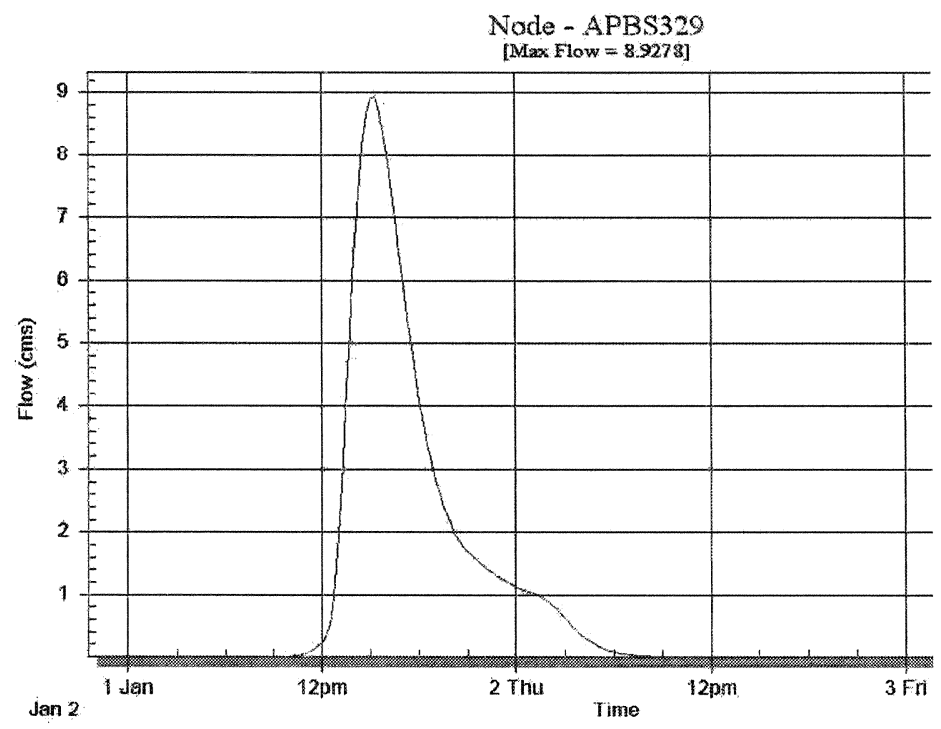

Figure 30.4 RUNOFF hydrograph from adjacent subcatchment stored at Node APBS329. 


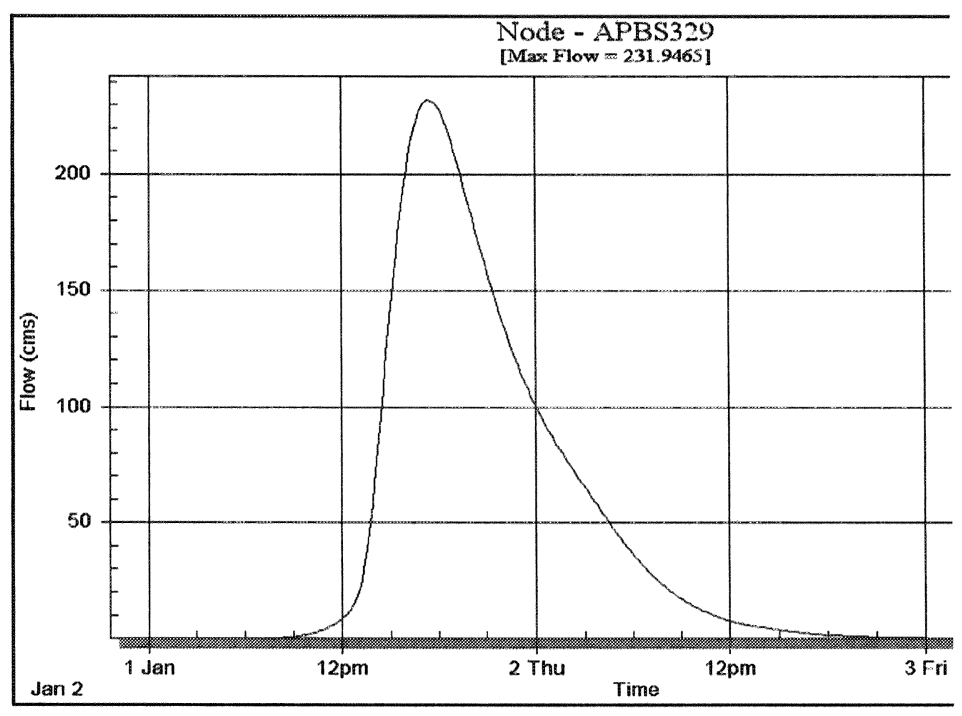

Figure 30.5 Routed TRANSPORT hydrograph at Node APBS329.

\subsubsection{Sensitivity Analysis}

Although any deterministic model is based on understanding the physics of the modeled system it, however, includes empirical components and is thus a compromise between limitations of available data, sound conceptualisation and model formulation (Hughes, 1991). An effective calibration of the empirical components of these models requires an understanding of which model parameters are most significant and under which conditions these parameters dominate. This understanding is obtained through a sensitivity analysis of the model parameters.

This sensitivity analysis essentially consists of repeatedly running the model whilst independently varying identified model parameters by an amount representative of the uncertainty in the parameter being analysed (James, 1994).

The sensitivity analysis allowed key system parameters to be identified in the generation of overland flow. Initial representative base values were assumed for each parameter in question and varied between $80 \%$ and $120 \%$ of the initial base value in order to rank the degree of sensitivity of each parameter.

Table 30.4, below, indicates the parameters selected for sensitivity analysis and the relative differences between outflows calculated with varied parameters and the flow calculated with base value for the Pienaars River. This results in the identification of the corresponding sensitivity of each parameter. 
Table 30.4 Variation of outflow for Pienaars River from variation of parameter values.

\begin{tabular}{ccccc}
\hline \multirow{2}{*}{ Parameter } & \multicolumn{4}{c}{ \%Variation of initial base values } \\
\cline { 2 - 5 } & 80 & 90 & 110 & 120 \\
\cline { 2 - 5 } CN & $-39 \%$ & $-22 \%$ & $27 \%$ & $51 \%$ \\
Tc & $13 \%$ & $6 \%$ & $-5 \%$ & $-10 \%$ \\
SF & $-3 \%$ & $-2 \%$ & $1 \%$ & $2 \%$ \\
\%imp & 0 & 0 & 0 & 0 \\
width & 0 & 0 & 0 & 0 \\
\hline
\end{tabular}

Sensitivity analysis of the Pienaars River revealed that $\mathrm{CN}$ and $\mathrm{Tc}$ were the most significant parameters requiring perturbation as indicated in Table 30.4, above, where increasing $\mathrm{CN}$ by $20 \%$ resulted in a $51 \%$ increase in outflow of the Pienaars River when compared with outflows calculated with the base values.

\subsubsection{Derivation of Calibration Flows}

Given the lack of accurate and reliable flow gauging data of sufficient duration, it was not possible to calibrate the model for low recurrence interval events against a recorded flow series. A regional frequency analysis was thus utilised on existing records (reduced to virgin non-urbanised conditions) to generate an index flood per homogenous area and together with growth curves and site scaling resulted in peak flows being generated for return periods from 2 to 200 $y$ at existing gauging stations. The objective of this frequency analysis was thus to utilise a recorded sample of gauged flows in order to estimate future probabilities of occurrence.

Additional deterministic and empirical flood determination techniques were assessed and a final adopted peak flow was determined from all the available data at available gauging stations for each return period. This approach was followed through out the entire CTMM modeling exercise but is discussed in terms of the calibration of the Apies River catchment, which from Table 30.1 above, can be seen to be the largest river system within the CTMM area.

The use of a regional approach has many benefits including robustness and increased reliability of at-site design values. The assumption when using an index-flood approach is that homogenous regions can be identified where the distribution of extreme events is the same, except for a local scaling factor (Smithers and Schulze, 2000). 
Design flow values are estimated by extracting the Annual Maximum Series (AMS) of all flow gauges within the Apies catchment. A number of stochastic parameters including arithmetic mean, median and log mean of each gauge's AMS were plotted against its corresponding catchment area. The arithmetic mean of AMS versus catchment area obtained the best regression. This allowed the derivation of the index flood from Equation 30.2 below:

where:

$$
\bar{Q}=(C \times A)^{B}
$$

$$
\begin{aligned}
\mathscr{Q} & =\text { index flood }\left(\mathrm{m}^{3} / \mathrm{s}\right) \\
C & =\text { catchment area }\left(\mathrm{km}^{2}\right), \text { and } \\
A, B & =\text { regression constants from Table } 30.5 \text { below. }
\end{aligned}
$$

The following probability distributions were applied to the ranked AMS for each gauge to derive regionalised growth curve parameters for each return period:

- GEV/MM - General Extreme Value with Mean of moments

- GEV/PWM - General Extreme Value with Probability Weighted Moments

- LN - Log Normal

- LP3 - Log-Pearson Type III

The value obtained from every probability distribution for each gauge was divided by its index flood derived from Equation 30.2, above, for each return period. The mean of these values for the different gauges resulted in a regionalised growth curve parameter per probability distribution for each return period. The average of these means provided a single regionalised growth curve parameter for the Apies Catchment for each required return period. These values are indicated in Table 30.5:

Table 30.5 Regionalised growth curve factors for Apies River.

\begin{tabular}{lcccccccccc}
\hline Catchment & \multicolumn{1}{c}{ Regionalised Growth factors per return period } & \multicolumn{2}{c}{ Mean flood factor } \\
\hline & 2 & 5 & 10 & 20 & 50 & 100 & 200 & A & B \\
Apies & 0.78 & 1.36 & 2.10 & 2.83 & 4.02 & 5.17 & 6.59 & 8.53 & 0.45 \\
\hline
\end{tabular}

These growth curve factors are applied to the Index flood obtained in Equation 30.2, above, in order to obtain peak flows at required gauging stations for different return periods as shown in Equation 30.3 below: 


$$
Q_{x_{R I}}=G \times \bar{Q}_{x}
$$

where:

$$
\begin{aligned}
Q_{x_{R I}} & =\text { peak flow at gauge } \mathrm{X} \text { for given } \mathrm{RI}\left(\mathrm{m}^{3} / \mathrm{s}\right), \\
G & =\text { growth curve parameter (Table } 30.5), \text { and } \\
Q_{x_{R I}} & =\text { index flood for gauge } \mathrm{X}\left(\mathrm{m}^{3} / \mathrm{s}\right) .
\end{aligned}
$$

Given the available flow record of these gauging stations, the above growth curve approach could not be applied with confidence over the higher return periods. Additional empirical and deterministic flood generation techniques were considered including:

- Midgley and Pitman Method (MIPI),

- HRU 1/72,

- Catchment Parameter Method (CAPA),

- Direct Hydrograph Method (DRH) HRU1/74,

- Regional Maximum Flood (RMF),

- Rational Method, and

- SCS-SA method.

to obtain final adopted peak values for all required return periods for virgin conditions for the available gauges in the Apies River catchment. These flows are indicated in Table 30.6, together with the Visual SWMM node corresponding to the flow gauge location.

Table 30.6 Adopted peak flows for stations on Apies River under Virgin catchment conditions.

\begin{tabular}{clccccccccc}
\hline Station & Model node & Area & \multicolumn{7}{c}{ Return Period $(\mathrm{y})$} \\
\hline & & $\left(\mathrm{km}^{2}\right)$ & 2 & 5 & 10 & 20 & 50 & 100 & 200 \\
\hline A2H062 & APWS70 & 8.1 & 16 & 30 & 44 & 59 & 85 & 110 & 139 \\
A2H063 & APDE274 & 30 & 31 & 64 & 94 & 126 & 180 & 228 & 292 \\
A2H057 & APSK444 & 66 & 52 & 86 & 118 & 157 & 246 & 324 & 419 \\
A2H007 & AP64968 & 142 & 63 & 109 & 169 & 228 & 394 & 504 & 734 \\
A2R002 & Bon Accord & 315 & 71 & 149 & 223 & 327 & 539 & 689 & 896 \\
A2H026 & AP9779 & 676 & 161 & 286 & 396 & 537 & 809 & 1023 & 1308 \\
\hline
\end{tabular}

\subsubsection{Calibration and Verification of VisualSWMM Model}

Following the derivation of adopted peak flows for virgin catchment conditions the model required calibration to match these flows. The objective functions in the calibration exercise were the design peak flows at the flow gauging 
stations for the $100 \mathrm{y}$ return period with the evaluation function being the percentage difference between these model-generated peak flows and the adopted virgin peak calibration flows.

From the sensitivity analysis the two most sensitive parameters to be altered in the calibration exercise were time of concentration (Tc) and curve number $(\mathrm{CN})$. Curve numbers were obtained for virgin conditions based on an overlay of SCS-SA soil distribution and pre-urbanised landuse with a degree of confidence.

The calibration approach to minimise the objection function was thus to firstly alter Tc within a realistic envelope of values uniformly across all subcatchments captured by the gauge in question. If this still did not minimise the objective function satisfactorily, the virgin $\mathrm{CN}$ would then be altered within a realistic envelope of values in a similar manner.

(Given that the number of calibration parameters significantly exceeded the number of observations, automated calibration techniques were ignored. This was to limit the futile exercise of generating a multitude of non-unique possible solutions oriented to minimising the evaluation function.)

Once the parameter set was calibrated for a given gauge, these values were kept constant for the calibration of the next downstream gauge with the same approach applied to the remainder of the downstream subcatchments.

Table 30.7 summarises the results of the calibration exercise at gauging stations on the Apies River for the 1 in 100 y flood event.

Table 30.7 Evaluation of objection function for calibration of Apies River.

\begin{tabular}{lccccc}
\hline Station & Model node & \multicolumn{4}{c}{ Area } \\
\hline & $\left(\mathrm{km}^{2}\right)$ & $\left(\mathrm{m}^{3} / \mathrm{s}\right)$ & $\left(\mathrm{m}^{3} / \mathrm{s}\right)$ & \\
\hline A2H062 APWS70 & 8.1 & 110 & 104 & 6 \\
A2H063 APDE274 & 30 & 228 & 226 & $<1$ \\
A2H057 APSK444 & 66 & 324 & 322 & $<1$ \\
A2H007 AP64968 & 142 & 504 & 505 & $<1$ \\
A2R002 Bon Accord & 315 & 689 & 694 & $<1$ \\
A2H026 AP9779 & 676 & 1023 & 1119 & 8 \\
\hline
\end{tabular}

Table 30.7 indicates that the calibration exercise, which entailed uniformly increasing Tc across all subcatchments within a gauged area (between $10 \%$ and $20 \%$ across all gauged areas), resulted in good agreement between the VisualSWMM model and the adopted peaks for calibration at 1 in $100 \mathrm{y}$ recurrence interval. This is also shown in Figure 30.6. 


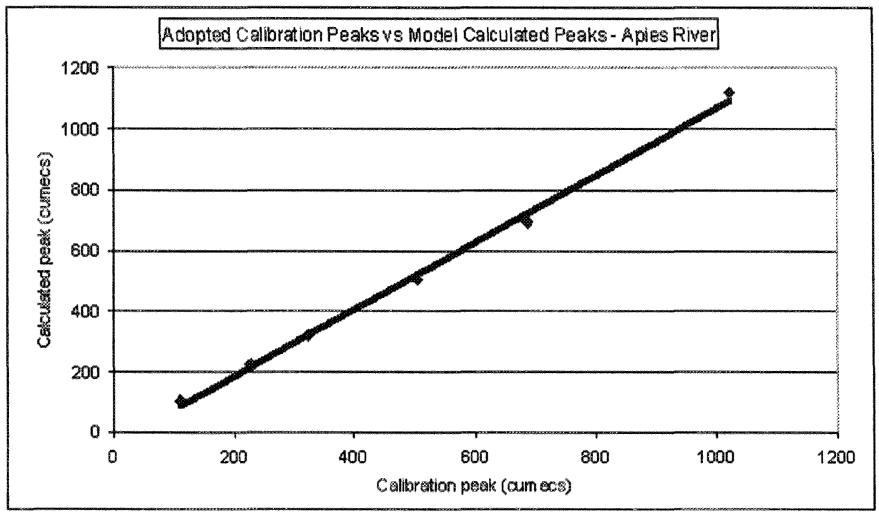

Figure 30.6 Adopted calibration peak flow vs. VisualSWMM calculated peak flow - Apies River.

Given the successful calibration of the key model parameters to the 100year flood data set, the parameter selection was then verified using different independent meteorological conditions, namely storms for the 2, 5, 10, 20, 50 and $200 \mathrm{y}$ return periods. The process is thus to test the model under different conditions to reveal inadequacies and hence find conditions for which the model is no longer appropriate. The results of the verification exercise are shown in Figures 30.7 to 30.9 , at three significant flow gauging stations.

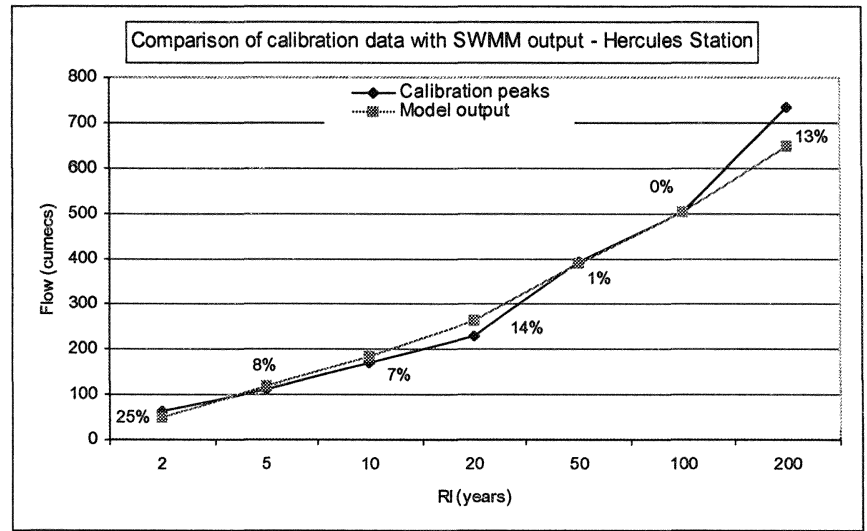

Figure 30.7 Comparison between model output and adopted peak flows Hercules Station 
Figure 30.7, above, provides a comparison between Apies model output and the adopted peak flows for calibration at the Hercules gauging station. The area captured by this gauge is $142 \mathrm{~km}^{2}$ of the upper parts of the Apies catchment that is now significantly affected by urbanisation. The model, calibrated to the 1 in 100 y recurrence interval flood, appears to mimic the verification data satisfactorily. It does appear, however, to underestimate the 1 in $2 \mathrm{y}$ and 1 in $200 \mathrm{y}$ floods whilst overestimating the 1 in $20 \mathrm{y}$ flood.

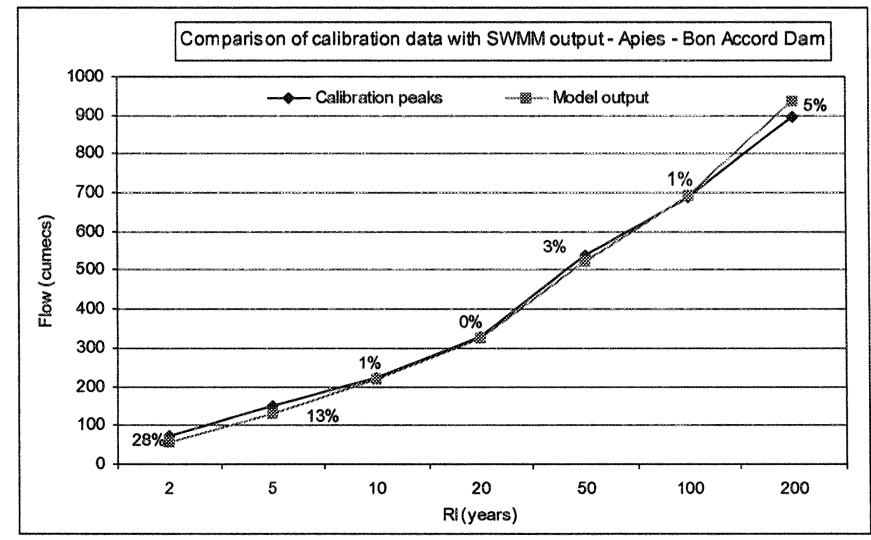

Figure 30.8 Comparison between model output and adopted peak flows Bon Accord Dam.

Figure 30.8 provides a similar comparison between the Apies model output and the adopted peak flows for calibration for a gauging station further down the catchment at the Bon Accord Dam. The accumulated area at this gauging station is $315 \mathrm{~km}^{2}$. The model output at this station mimics the verification data very well for floods from the 1 in $10 \mathrm{y}$ flood up to the 1 in 200 $\mathrm{y}$ flood. It does appear to underestimate flows for the 1 in 2 and 1 in $5 \mathrm{y}$ floods.

It is noted that given the accumulated area up to this gauging station, model calibration and verification inadequacies at the gauging stations upstream will also be accumulated to this point. This is highlighted in Figure 30.9, which displays the comparison between model outflow and adopted peak flows for the most downstream gauging station on the Apies River in CTMM jurisdiction at the Leeukraal Dam. This represents an area of $676 \mathrm{~km}^{2}$ of mixed landuse including urbanised, agricultural and undeveloped areas.

Whilst performing satisfactorily for the 1 in $20 \mathrm{y}$ to 1 in $200 \mathrm{y}$ recurrence interval events, the model for the Apies River catchment significantly underestimates the high recurrence interval 1 in 2, 5 and 10-y events. The magnitude 


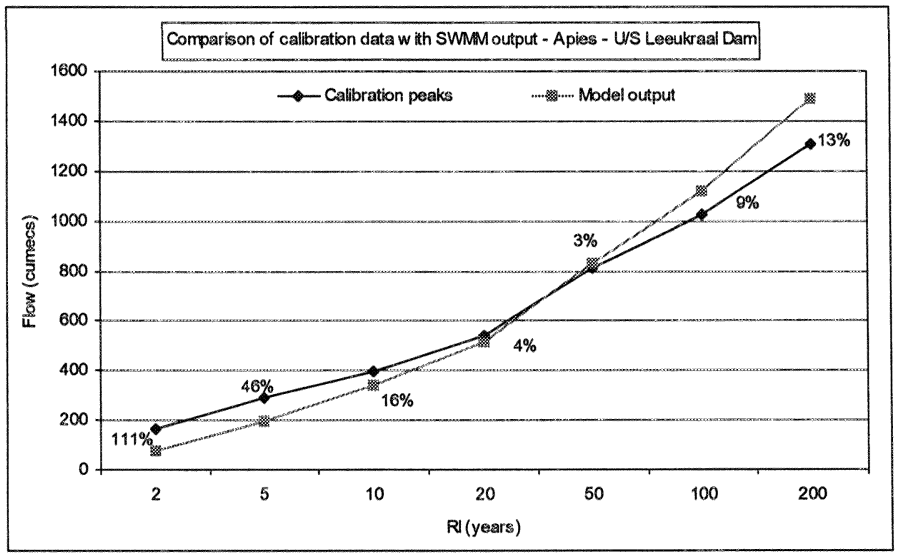

Figure 30.9 Comparison between model output and adopted peak flows Leeukraal Dam.

of this underestimation ( $111 \%$ for the 1 in $2 \mathrm{y}$ storm) can be as a result of the accumulation of underestimations for all gauges up to this point yet is also possibly caused by inadequacies in the model assumptions.

These assumptions and other sources of error could include:

- calibrating the model to 1 in $100 \mathrm{y}$ event that is unlikely to have been captured in the existing flow record as opposed to the higher recurrence interval events for which data is more readily available;

- using flow gauge data from gauging stations calibrated to recording low flow conditions;

- the assumption of deriving adopted calibration peaks from a mean of stochastically generated flood flows from regional analysis and conservative empirical flood generation techniques;

- reating control structures as diversion structures thereby not considering the full dampening of peak flows at these structures due to backwater storage effects;

- assumptions inherent in SCS method of runoff generation; and

- the assumption that $\mathrm{CN}$ and $\mathrm{Tc}$ are constant parameters independent of recurrence interval.

Given the above limitations for the high recurrence intervals, the VisualSWMM model behaves satisfactorily at low recurrence interval storms for 1 in 20,50 and 100-y events. It is for these events that the majority of infrastructure is designed to accommodate. 
To obtain integrated flow data for present and future conditions, curve numbers were adjusted to reflect planned developments in landuse. The model was re-rerun with increased curve numbers and the associated increase in flow for the Apies River at the most downstream flow gauge is shown in Figure 30.10 , with the 1 in 100 y flow increasing from $1120 \mathrm{~m}^{3} / \mathrm{s}$ to $1460 \mathrm{~m}^{3} / \mathrm{s}$.

Output from the model is in terms of peak flows and volumes at various recurrence interval events from individual subcatchments and tributaries up to total catchment outflow. This spatially related flow information thus forms the basis of a Stormwater Management Information System (SMIS) to be used in catchment management decision-making. This is in terms of providing data for reliable flood line determination needed for urban development as well as assisting in the integrated planning of roads, culverts and other associated infrastructure.

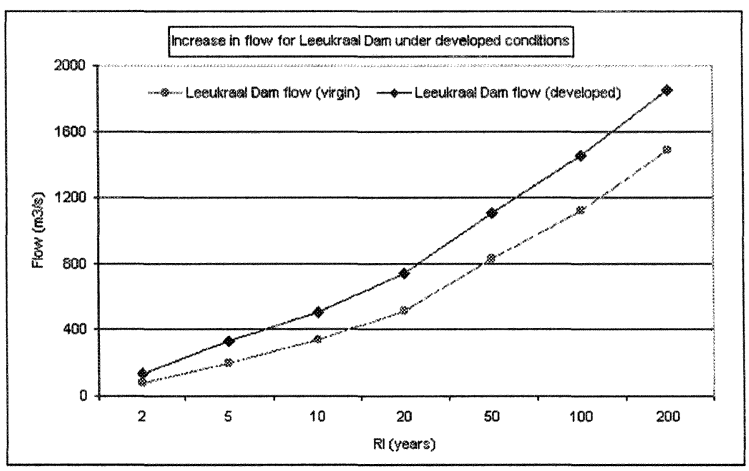

Figure 30.10 Expected increase in flow due to proposed development Apies River catchment .

\subsection{Conclusions}

Distributed hydrological models can play a significant role in catchment management through the provision of flow data for the integrated planning of urban development and infrastructure. These models structure knowledge whilst indicating limitations in available data to be rectified for future modeling applications.

This chapter presents a generic approach to the derivation of regional hydrological models to be used in aiding catchment management decisionmaking. This is illustrated in the derivation of the CTMM hydrological model generated in VisualSWMM. The approach allows for the derivation of design 
peak flows at various recurrence interval events using regional frequency analyses to derive spatially distributed rainfall and flow gauging data. The model is calibrated and verified using peak flows derived for virgin conditions given the need for the simulation of low recurrence interval events. The model is then adjusted to account for present and future planned urbanisation.

The derivation of the model is significantly aided by the use of GIS to allow the effective use of spatial geographic information and the transformation of this information into representative variables for hydrological simulation. This parameter estimation is accomplished with increased accuracy and efficiency through an integrated analysis of the various data sets using spatial overlay capabilities. The ability of GIS to display thematic representations of data also results in it being an effective communication medium for the widespread diffusion of information.

The CTMM model, using the results obtained for the Apies River as example for the purposes of this chapter, showed good agreement between calculated peak flows and adopted peak calibration flows for virgin conditions for low recurrence intervals. It was shown, however, to underestimate the high recurrence interval events possibly through errors related to:

- flow gauging data not representative of peak flows due to calibration to base flow conditions;

- calibrating model to 1 in $100 \mathrm{y}$ event which is extrapolated from records of a shorter duration and derived from stochastic and empirical flood generation techniques;

- neglecting full consideration of flood attenuation at control structures by considering as mere diversion structures; and

- inherent limitations in assumptions underlying SCS runoffmethod and the assumption that key model parameters, Tc and $\mathrm{CN}$ remain constant for all recurrence interval events.

It is intended to revisit the model generated for the CTMM to address part of the above-identified uncertainties. This is in terms of the recalibration of existing flow gauging structures to improve the determination of peak flow in flood events as well as the reformulation of significant control structures as storage devices with outflow generated by rating curve for bridge and culvert openings.

Given its output in terms of peak flow and volume at various recurrence interval events for scales ranging from tertiary subcatchment to quaternary catchment, the regional CTMM hydrological model serves well as a master drainage plan in providing data for stormwater management aspects of catchment management. 


\section{Acknowledgment}

Acknowledgment is given to City of Tshwane Metropolitan Municipality (Transportation, Engineering and Roads Department) for use of relevant data.

\section{Bibliography}

Bailey, A. K. and Kakebeeke, J. P. (1991) The role of GIS with particular relevance to the hydrological field. In: Proceedings of the Fifth South African National Hydrological Symposium. SANCIAHS. Stellenbosch. pp. 9A-2-1-9A-2-6.

Cowen, D. J (1988) GIS versus CAD versus DBMS: what are the differences? Photogrammetric Engineering and Remote Sensing. Longman. London, pp. 15511554

Fisher, A and Wijers, B.E. W (1991) The application of GIS in water resources systems modelling in the Mogalakwena River Basin Study. In: Proceedings of the Fifth South African National Hydrological Symposium. SANCIAHS. Stellenbosch. pp. 9A-1-1-9A-1-5.

Görgens, A. H. M., Pegram, G. C., Uys, M., Grobicki, A., Loots, L., Tanner, A., and Bengu, R. (1998) Guidelines for Catchment Management to achieve Integrated Water Resources Management in South Africa . WRC Report. Pretoria. KV 108/ 98.

Herald, J. R (1991) GIS: a tool for the hydrological modeller. In: Proceedings of the Fifth South African National Hydrological Symposium. SANCIAHS. Stellenbosch. pp.9B-3-1-9B-3-7.

Hughes, D.A. (1991) Catchment Hydrological Modelling: Where are we and where do we go from here? Proceedings of Fifth South African National Hydrological Symposium. SANCIAHS. Stellenbosch. pp. 2.1.1-2.1.10.

James, W (1994) RULES for RESPONSIBLE MODELLING. CHI. Guelph, Ontario.

James, W. P. and James, W. R. C. (1997) Hydrology - A guide to the Rain, Temperature and Runoff modules of the USEPA SWMM4. Computational Hydraulics Inc (CHI). Guelph, Canada.

Males, R.J (2001) Complex, deterministic hydrological modelling towards Decision Support for Urban Catchment Management. Unpublished MSc Eng thesis. University of Stellenbosch.

Midgley, D.C., Pitman, W.V., Middleton, B.J. (1994) Surface Water Resources of South Africa. 1990. WRC Report. Pretoria. 298/1.1/94.

Smithers, J.C and Schulze, R.E (2002) The estimation of Design Rainfall for Tshwane - Report to SRK Consulting. School of Bioresources Engineering and Environmental Hydrology. Pietermaritzburg. ACRUcons Report 38.

Yen, B.C. (1994) Is hydraulics over-used or under-used in storm drainage? Water Science \& Technology, 29 (1-2): pp. 53-61. 